\title{
The anti-parasitic efficacy of ivermectin and pyrantel pamoate compound against canine Toxocara canis and Trichuris vulpis
}

\author{
Heejeong Youn ${ }^{1, *}$, Jeong Chan $\mathrm{Ra}^{2}$, Byung Ki Kim², Bokyoung Bae${ }^{1}$, Yong Suk Lim , \\ Kyong Hee Kim ${ }^{1}$, Kyong-Eun Lee ${ }^{1}$ \\ ${ }^{I}$ Department of Veterinary Parasitology, College of Veterinary Medicine, Seoul National University, \\ Seoul 151-742, Korea \\ ${ }^{2}$ RNL-Bio, Seoul 138-840, Korea \\ (Received: February 18, 2011; Revised: November 11, 2011; Accepted: November 12, 2011)
}

\begin{abstract}
Toxocara (T.) canis and Trichuris (T.) vulpis are very important canine parasitic nematodes. $T$. canis parasitize in small intestine and T. vulpis parasitize in large intestine. In order to control of these nematodes, ivermectin and pyrantel pamoate compound was applied to the dogs infected with these parasites naturally and artificially. This drug was composed of $68.0 \mu \mathrm{g}$ of ivermectin and $57.0 \mathrm{mg}$ of pyrantel pamoate for small animal, $136.0 \mu \mathrm{g}$ of ivermectin and $114.0 \mathrm{mg}$ of pyrantel pamoate for middle animal, and $272.0 \mu \mathrm{g}$ of ivermectin and $227.0 \mathrm{mg}$ of pyrantel pamoate for large animal. Ivermectin in this drug is activity to nematodes and ectoparisites. Pyrantel pamoate in this drug is also activity to nematodes. In this experiment, this drug had a good efficacy against $T$. canis and $T$. vulpis in the infected dogs.
\end{abstract}

Keywords : ivermectin, ivermectin and pyrantel pamoate compound, pyrantel pamoate, Toxocara canis, Trichuris vulpis

\section{Introduction}

Companion animals are very important to human and families, because they give many comfortable, communications, and human-relationship between their families. If they are infected with parasites and zoonotic parasites, their parasites can infect to human. Military dogs and police dogs are frequently infected with parasites. The major parasites in dogs are T. canis, T. vulpis, and Dirofilaria (D.) immitis in helminth, Isospora (I.) canis and Giardia (G.) canis in protozoa, and sarcoptic mite [20]. Ivermectin is a kind of good anti-parasitic drug against nematodes, such as Toxocara (T.) canis, Trichuris (T.) vulpis, ect and ectoparasites in dogs [1,7]. Pyrantel pamoate is also very good anti-parasitic drug against canine nematodes, such as Ancylostoma caninum, $T$. canis, T. vulpis, and so on $[10,12,14,18]$. This is the research on the anti-parasitic efficacy and safety of ivermectin and pyrantel pamoate compound (IPPC) against $T$. canis and $T$. vulpis of companion animals. After the anti-parasitic activities of the IPPC were evaluated in the center of strayed dogs and private animal clinics, its were re-evaluated in the private animal clinics.

\section{Materials and Methods}

\section{Experimental Animals and feed}

Experimental animals are companion animals (dogs) and deserted dogs infected with $T$. canis and $T$. vulpis. They were investigated eggs of parasites. In the field trial, the experimental dogs from the private animal clinics in Seoul were used in this experiment. Feed and water were supplied ad libitum.

\section{Drugs and parasites}

The components and dosages of IPPC were as follows. This experiment was used drug for middle animal and other ivermectin drug. For small animals, the effective components of IPPC were $68.0 \mu \mathrm{g}$ of ivermectin and $57.0 \mathrm{mg}$ of pyrantel pamoate in 1 tablet. And for large animals, those were $272.0 \mu \mathrm{g}$ of ivermectin and $227.0 \mathrm{mg}$ of pyrantel pamoate in 1 tablet.

*Corresponding author

Tel: +82-2-880-1267, Fax: +82-2-888-0659

E-mail: younhj@snu.ac.kr 
These drugs were evaluated the anti-parasitic activity against $T$. canis and $T$. vulpis in the center of stray dogs and private clinics.

IPPC was used in this experiment. The dogs infected with $T$. canis and $T$. vulpis were used in this experiment.

\section{Methods}

T. canis and T. vulpis was investigated in the center of stray dogs and private animal clinics. After investigation of parasites infection in the stray dogs, the infected dogs were used this experiment. Experimental groups and investigated items were as follow Tables 1 and 2. The dogs were raised by use of in the center of stray dogs and private animal owners. After the parasitic infections of the dogs were diagnosed by use of feces in animal clinics, IPPC were administered orally to the dogs infected with $T$. canis and $T$. vulpis. In the private animal clinics trials, the experimental groups and investigated items were as follow Tables 3 and 4 . The drugs also were administered per oral. The dogs were raised by use of in the private animal owners.

\section{Experimental groups}

Forty five dogs infected with $T$. canis and T. vulpis were divided three groups, each group was 3 dogs, such as IPPC (1, 2 and 4 doses) treated group, other ivermectin drug group and infected control group. These experiments were replied 3 times, respectively. In the field trial, twenty dogs in the private animal clinics were selected and were experimented. One group was control group and other group was IPPC treated group.

\section{Investigated items}

Eggs of $T$. canis and T. vulpis were investigated in the feces at 0,2 , and 4 weeks before and after treatment. Egg reduction rates were calculated each week after treatment. To evaluate drug safety, the side-effects of 2and 4-fold treated groups were investigated at 0,2 , and

Table 1. The anti-parasitic efficacies of ivermectin and pyrantel pamoate compound (IPPC) against Toxocara (T.) canis in the center of stray dogs

\begin{tabular}{|c|c|c|c|c|c|c|c|}
\hline \multirow{3}{*}{ Groups } & \multirow{3}{*}{$\begin{array}{l}\text { No. of } \\
\text { animals }\end{array}$} & \multirow{3}{*}{ Replication } & \multirow{3}{*}{ Treatment } & \multicolumn{4}{|c|}{ Investigated items } \\
\hline & & & & \multicolumn{3}{|c|}{ Reduction rates of eggs (Infected rates) } & \multirow{2}{*}{ Symptoms } \\
\hline & & & & 2 weeks & \multicolumn{2}{|c|}{4 weeks } & \\
\hline Infected control & 3 & 3 & No & $-7.1(0.0)$ & \multicolumn{2}{|c|}{$13.1(0.0)$} & No \\
\hline IPPC & 3 & 3 & Yes & $94.4(66.7)$ & \multicolumn{2}{|c|}{$100.0(100.0)$} & No \\
\hline Ivermectin & 3 & 3 & Yes & $88.6(44.4)$ & \multicolumn{2}{|c|}{$100.0(100.0)$} & No \\
\hline IPPC (2D) & 3 & 3 & Yes & $97.4(77.8)$ & \multicolumn{2}{|c|}{$100.0(100.0)$} & No \\
\hline IPPC (4D) & 3 & 3 & Yes & $100.0(100.0)$ & \multicolumn{2}{|c|}{$100.0(100.0)$} & No \\
\hline \multirow{2}{*}{ No. of Dog } & \multirow{2}{*}{\multicolumn{2}{|c|}{ Treatment }} & \multicolumn{5}{|c|}{ Weeks after treatment } \\
\hline & & & 0 & \multicolumn{3}{|c|}{2} & 4 \\
\hline \multirow{4}{*}{ Control } & \multicolumn{2}{|c|}{ Total } & $16,800(9 / 9)$ & \multirow{2}{*}{\multicolumn{2}{|c|}{$\begin{array}{c}18,000(9 / 9) \\
2000\end{array}$}} & \multicolumn{2}{|c|}{$14,600(9 / 9)$} \\
\hline & \multicolumn{2}{|c|}{ Mean } & 1,867 & & & & 1,622 \\
\hline & \multicolumn{2}{|c|}{$\pm \mathrm{SD}$} & 1,330 & \multicolumn{3}{|c|}{1,661} & 891 \\
\hline & & tal & $18,000(9 / 9)$ & & & & $0(0 / 9)$ \\
\hline IPPC 1D & & ean & 2,000 & & & & 0 \\
\hline & & SD & 1,723 & & & & 0 \\
\hline & & tal & $14,000(9 / 9)$ & & & & $0(0 / 9)$ \\
\hline Ivermectin & & ean & 1,556 & & & & 0 \\
\hline & & SD & 646 & & & & 0 \\
\hline & & tal & $15,400(9 / 9)$ & & & & $0(0 / 9)$ \\
\hline IPPC 2D & & ean & 1,711 & & & & 0 \\
\hline & & SD & 813 & & & & 0 \\
\hline & & tal & $14,400(9 / 9)$ & & & & $0(0 / 9)$ \\
\hline IPPC 4D & & ean & 1,600 & & & & 0 \\
\hline & & SD & 447 & & & & 0 \\
\hline
\end{tabular}


4 weeks before and after treatment.

\section{Statistic analysis}

Statistic analysis were accompanied by student's $t$ test by use of SigmaPlot (ver. 5.0; Jandel, USA).

\section{Results}

The anti-parasitic efficacies of IPPC against $T$. canis and T. vulpis in the center of stray dogs

In the results of Anti-parasitic efficacy of IPPC against T. canis, the egg reduction rate of IPPC treated group was $94.4 \%$ and other Ivermectin treated group was $88.6 \%$ after 2 weeks post treatment. Those of 2- and 4doses groups were $97.4 \%$ and $100 \%$, respectively. The individual egg reduction rates of IPPC treated group and other ivermectin treated group were $66.7 \%$ and $44.4 \%$, respectively. The egg reduction rates of all treated groups were $100 \%$ after 4 weeks post treatment (Table 1).

In the results of Anti-parasitic efficacy of IPPC against
T. vulpis, the egg reduction rate of IPPC treated group was $84.4 \%$ and other ivermectin group was $85.7 \%$ after 2 weeks post treatment. Those of 2- and 4-doses groups were $93.5 \%$ and $97.2 \%$, respectively. The individual egg reduction rates of IPPC treated group and other ivermectin group were $44.4 \%$, respectively. Those of 2and 4-doses groups were $55.6 \%$ and $77.8 \%$, respectively. The egg reduction rate of IPPC treated group was $96.7 \%$ and other ivermectin group was $97.1 \%$ after 4 weeks post treatment. Those of 2- and 4-doses groups were $98.7 \%$ and $100.0 \%$, respectively. The individual egg reduction rates of IPPC treated group and other ivermectin group were $77.8 \%$, respectively. Those of $2-$ and 4-doses groups were $88.9 \%$ and $100.0 \%$, respectively (Table 2).

The anti-parasitic efficacies of IPPC to T. canis and $T$. vulpis in the private clinics

Egg reduction rate of $T$. canis in blood was $95.0 \%$ in the group treated with IPPC. Individual egg reduction

Table 2. The anti-parasitic efficacies of IPPC against Trichuris (T.) vulpis in the center of stray dogs

\begin{tabular}{|c|c|c|c|c|c|c|}
\hline \multirow{3}{*}{ Groups } & \multirow{3}{*}{$\begin{array}{l}\text { No. of } \\
\text { animals }\end{array}$} & \multirow{3}{*}{ Replication } & \multirow{3}{*}{ Treatment } & \multicolumn{3}{|c|}{ Investigated items } \\
\hline & & & & \multicolumn{2}{|c|}{ Reduction rates of eggs (Infected rates) } & \multirow{2}{*}{ Symptoms } \\
\hline & & & & 2 weeks & 4 weeks & \\
\hline Infected control & 3 & 3 & No & $-8.0(11.1)$ & $14.7(0.0)$ & No \\
\hline IPPC & 3 & 3 & Yes & $84.4(44.4)$ & $96.7(77.8)$ & No \\
\hline Ivermectin & 3 & 3 & Yes & $85.7(44.4)$ & $97.1(77.8)$ & No \\
\hline IPPC (2D) & 3 & 3 & Yes & $93.5(55.6)$ & $98.7(88.9)$ & No \\
\hline IPPC (4D) & 3 & 3 & Yes & $97.2(77.8)$ & $100.0(100.0)$ & No \\
\hline \multirow{2}{*}{ No. of Dog } & \multirow{2}{*}{\multicolumn{2}{|c|}{ Treatment }} & \multicolumn{4}{|c|}{ Weeks after treatment } \\
\hline & & & 0 & 2 & \multicolumn{2}{|r|}{4} \\
\hline \multirow{3}{*}{ Control } & \multicolumn{2}{|c|}{ Total } & $15,000(9 / 9)$ & $16,200(8 / 9)$ & 12,8 & $0(9 / 9)$ \\
\hline & \multicolumn{2}{|c|}{ Mean } & 1,667 & 1,800 & \multicolumn{2}{|c|}{1,422} \\
\hline & \multicolumn{2}{|c|}{$\pm \mathrm{SD}$} & 1,330 & 1,661 & \multicolumn{2}{|c|}{891} \\
\hline \multirow{4}{*}{ IPPC 1D } & \multicolumn{2}{|c|}{ Total } & $18,000(9 / 9)$ & $2,800(5 / 9)$ & \multicolumn{2}{|c|}{$600(2 / 9)$} \\
\hline & \multicolumn{2}{|c|}{ Mean } & 2,000 & 311.1 & \multicolumn{2}{|c|}{66.7} \\
\hline & \multicolumn{2}{|c|}{$\pm \mathrm{SD}$} & 1,723 & 401.4 & \multicolumn{2}{|c|}{141.4} \\
\hline & \multicolumn{2}{|c|}{ Total } & $14,000(9 / 9)$ & $2,000(5 / 9)$ & \multicolumn{2}{|c|}{$400(2 / 9)$} \\
\hline \multirow[t]{3}{*}{ Ivermectin } & \multicolumn{2}{|c|}{ Mean } & 1,556 & 222.2 & \multicolumn{2}{|c|}{44.4} \\
\hline & \multicolumn{2}{|c|}{$\pm \mathrm{SD}$} & 646 & 253.9 & \multicolumn{2}{|c|}{88.2} \\
\hline & \multicolumn{2}{|c|}{ Total } & $15,400(9 / 9)$ & $1,000(4 / 9)$ & \multicolumn{2}{|c|}{$200(1 / 9)$} \\
\hline IPPC 2D & & ean & 1,711 & 111.1 & & 2.2 \\
\hline & & SD & 813 & 145.3 & & 6.6 \\
\hline & & tal & $14,400(9 / 9)$ & $400(2 / 9)$ & & $(0 / 9)$ \\
\hline IPPC 4D & & ean & 1,600 & 44.4 & & 0.0 \\
\hline & & SD & 447 & 88.2 & & 0.0 \\
\hline
\end{tabular}


292 Heejeong Youn, Jeong Chan Ra, Byung Ki Kim, Bokyoung Bae, Yong Suk Lim, Kyong Hee Kim, Kyong-Eun Lee

Table 3. The anti-parasitic efficacies of IPPC against $T$. canis in the private clinics

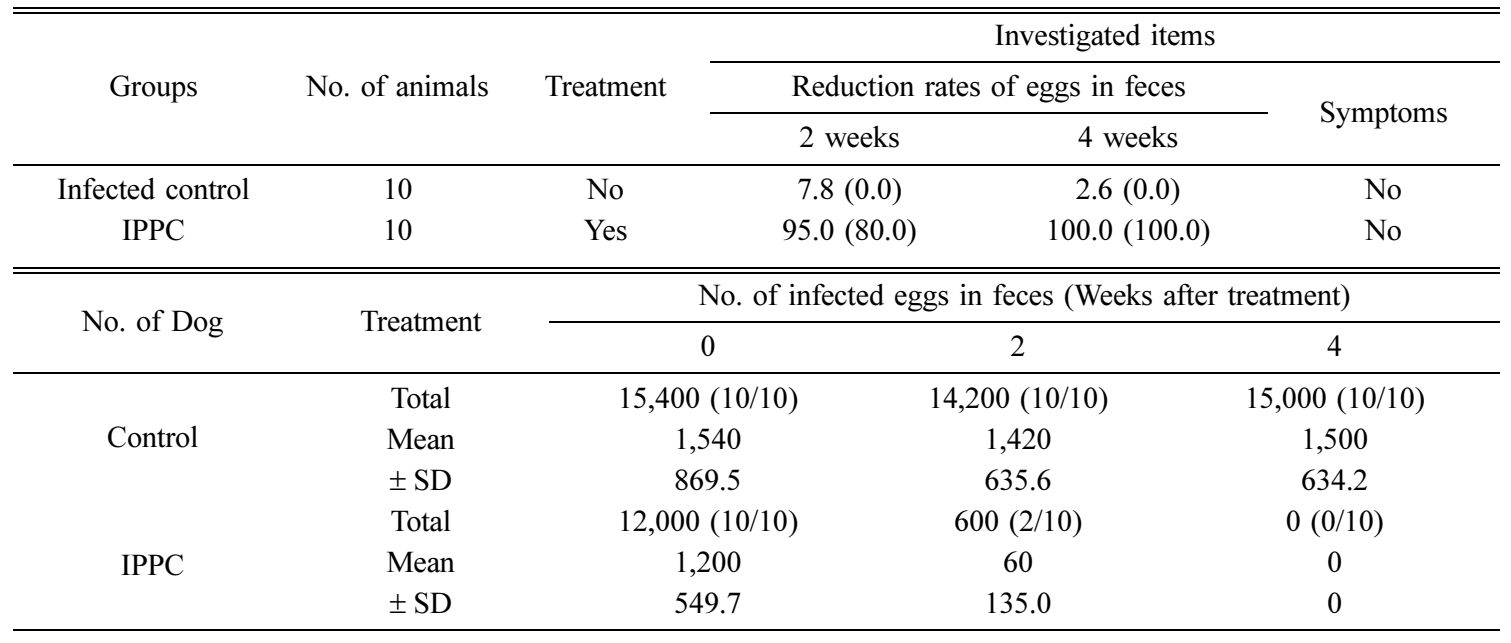

Table 4. The anti-parasitic efficacies of IPPC against $T$. vulpis in the private clinics

\begin{tabular}{|c|c|c|c|c|c|}
\hline \multirow{3}{*}{ Groups } & \multirow{3}{*}{ No. of animals } & \multirow{3}{*}{ Treatment } & \multicolumn{3}{|c|}{ Investigated items } \\
\hline & & & \multicolumn{2}{|c|}{ Reduction rates of eggs in feces } & \multirow{2}{*}{ Symptoms } \\
\hline & & & 2 weeks & 4 weeks & \\
\hline Infected control & 10 & No & $9.0(0.0)$ & $3.0(0.0)$ & No \\
\hline IPPC & 10 & Yes & $84.8(60.0)$ & $95.7(80.0)$ & No \\
\hline \multirow{2}{*}{ No. of Dog } & \multirow{2}{*}{ Treatment } & \multicolumn{4}{|c|}{ Weeks after treatment } \\
\hline & & & & 2 & 4 \\
\hline \multirow{4}{*}{ Control } & Total & 13,40 & 10) & $12,200(10 / 10)$ & $13,000(10 / 10)$ \\
\hline & Mean & & & 1,220 & 1,300 \\
\hline & $\pm \mathrm{SD}$ & & & 635.6 & 634.2 \\
\hline & Total & 9,200 & & $1,400(4 / 10)$ & $400(2 / 10)$ \\
\hline \multirow[t]{2}{*}{ IPPC } & Mean & & & 140 & 40 \\
\hline & $\pm \mathrm{SD}$ & & & 211.9 & 84.3 \\
\hline
\end{tabular}

rate of $T$. canis in blood was $80.0 \%$ in the group treated with IPPC at 2 weeks after treatment. Egg reduction rate of T. canis in blood was $100 \%$ in the group treated with IPPC (Table 3).

Egg reduction rate of $T$. vulpis in blood was $84.7 \%$ in the group treated with IPPC. Individual egg reduction rate of T. vulpis in blood was $60.0 \%$ in the group treated with IPPC at 2 weeks after treatment. Egg reduction rate of T. vulpis in blood was $95.7 \%$ in the group treated with IPPC. Individual egg reduction rate of T. vulpis in blood was $80.0 \%$ in the group treated with IPPC at 4 weeks after treatment (Table 4).

\section{Discussion}

The major canine parasites are round-worm, whipworm and heart-worm in nematodes, Isospora canis and Giardia canis, in protozoa, and mite in arthropods. In the results of anti-parasitic activity of IPPC against $T$. canis in this experiment, the egg reduction rate of IPPC treated and other ivermectin groups were $94.4 \%$ and $88.6 \%$ at 2 weeks after treatment, respectively. Those of 2 and 4 doses of IPPC group were $97.4 \%$ and 100\%, at 2 weeks after treatment, respectively. Otherwise, the individual egg reduction rate of IPPC treated and other ivermectin groups were $66.7 \%$ and $44.4 \%$ at 2 weeks 
after treatment, respectively. Those of 2 and 4 doses of IPPC group were $77.8 \%$ and $100 \%$, at 2 weeks after treatment, respectively. T. canis were treated in the all of the medicated groups at 4 weeks after treatment. In the field trials, the results of anti-parasitic activity of IPPC against $T$. canis, the egg reduction rate of IPPC treated group was $95.0 \%$ at 2 weeks after treatment. The individual egg reduction rate of IPPC treated group were $80.0 \%$ at 2 weeks after treatment. All of $T$. canis were entirely treated in the medicated groups at 4 weeks after treatment. Some researchers published the anti-parasitic efficacies of pyrantel parmoate and ivermectin against T. canis and T. vulpis. Miró et al. [16] reported that in the dogs, the anti-parasitic activities of pyrantel, fenbendazole, and febantel-pyrantel-praziquantel were $100 \%, \quad 80 \sim 100 \%$ and $97 \sim 100 \%$ against $T$. canis, respectively. Grandemange et al. [8] reported that in the dogs, the anti-parasitic activities of oxantel/pyrantel/ praziquantel against $T$. canis were $99.1 \%, 98.8 \%$ and $98.9 \%$ at 7,14 and 21 after medication. McTier et al. [15] reported that in the dogs, the results of anti-parasitic activity of selamectin and pyrantel against $T$. canis were 84.6 100.0\%. Dryden and Ridley [6] reported that in the dogs, the anti-parasitic activities of egg reduction rates of fenbendazole and pyrantel pamoate suspension against T. canis were $95.8 \%, 99.8 \%$ and $96.8 \sim 99.8 \%$, $85.8 \%, 88.3 \%$ and $71.4 \sim 98.3 \%$ at 10,31 and $31 \sim 128$ days after treatment, respectively. Lloyd and Gemmell [13] reported that in the dogs, the anti-parasitic activities of a compound of praziquantel, pyrantel embonate, and febantel were $100 \%$ in the artificial infection and 97 98\% in the field trial. Clark et al. [3] reported that in the dogs, the anti-parasitic activity of beef-based chewable formulation of Ivermectin and pyrantel pamoate against $T$. canis was $90.1 \%$, respectively. Clark et al. [2] reported that in the dogs, the anti-parasitic activities of pyrantel pamoate with $2.5,5$ or $10 \mathrm{mg} / \mathrm{kg}$ of weight against $T$. canis adult worms were 76.1, 94.2, 91.2\%, respectively. Jacobs [11] reported that in the dogs, the anti-parasitic activities of pyrantel pamoate and piperazine against $T$. canis adult worms were 83.5 and $82.5 \%$, respectively. Sharp and McCurdy [19] reported that in the dogs, the anti-parasitic activities of 10 and $1 \mathrm{mg} /$ $\mathrm{kg}$ of body weight of febantel and praziquantel against T. canis adult worms were $100 \%$, respectively. Corwin et al. [5] reported that the anti-parasitic activities of a compound of $3.40 \%$ febantel and $0.34 \%$ praziquantel against $T$. vulpis (10), T. canis (2), D. immitis (3) in the dogs and Toxocara cati (10/11) in the cats at 1 time per day during 3 days were $100 \%$, respectively. Corwin et al. [4] reported that febantel were good efficacy against nematodes, such as Ancylostoma caninum, T. vulpis, Uncinaria stenocephala, T. canis, Toxascaris leonina and cestodes, such as Taenia sp and Dipylidium caninum. In these experiments, the results of anti-parasitic activities of IPPC against $T$. canis were like as those of previous researchers.

The egg reduction rates of IPPC in the dogs artificially infected with T. vulpis were $84.4 \%$ in 1 dose, $93.5 \%$ in 2 doses, $97.2 \%$ in 4 doses and $85.7 \%$ in control drug treated group at 2 weeks after treatment. The individual egg reduction rates of IPPC against $T$. vulpis were $44.4 \%$ in 1 dose, $55.6 \%$ in 2 doses, $77.8 \%$ in 4 doses and $44.4 \%$ in control drug treated group at 2 weeks after treatment. The egg reduction rates of IPPC against $T$. vulpis were $96.7 \%$ in 1 dose, $98.7 \%$ in 2 doses, $100.0 \%$ in 4 doses and $97.1 \%$ in control drug treated group at 4 weeks after treatment. The individual egg reduction rates of IPPC against $T$. vulpis were $77.8 \%$ in 1 dose, $88.9 \%$ in 2 doses, $100.0 \%$ in 4 doses and $77.8 \%$ in control drug treated group at 4 weeks after treatment. In the field trials, the egg reduction rates of IPPC in the dogs infected with T. vulpis were $84.7 \%$ and $95.7 \%$ at 2 and 4 weeks after treatment. The individual egg reduction rates of IPPC in the dogs infected with $T$. vulpis were $60.0 \%$ and $80.0 \%$ at 2 and 4 weeks after treatment. Grandemange et al. [8] reported that the egg reduction rates of a compound of oxantel/pyrantel/ praziquantel against T. vulpis were $97.3 \%, 97.2 \%$ and $98.4 \%$ at 7,14 and 21 days after treatment, respectively. Prelezov and Bauer [17] reported that the worm reduction rates of Flubenol and Drontal Plus against $T$. vulpis were $99.4 \%$, respectively. Lloyd and Gemmell [13] reported that the anti-parasitic activities of a compound of praziquantel, pyrantel embonate and febantel were over $92 \%$ in the dogs naturally infected with T. vulpis. Greiner et al. [9] reported that the antiparasitic activities of febantel/praziquantel paste and febantel tablet were $95.8 \%$ and $99.7 \%$ in the dogs naturally infected with $T$. vulpis, respectively. Sharp and McCurdy [19] reported that the anti-parasitic activities of a compound of $10 \mathrm{mg} / \mathrm{kg}$ febantel and $1 \mathrm{mg} / \mathrm{kg}$ praziquantel was $99.5 \%$ in the dogs infected with $T$. vulpis at 1 time per day during 3 days. Corwin et al. [5] reported that the anti-parasitic activities of a compound of $3.40 \%$ febantel and $0.34 \%$ praziquantel 
against $T$. vulpis were $99.9 \%$ at 1 time per day during 3 days. The results of anti-parasitic activities of IPPC against T. vulpis also were like as those of previous researchers.

So that IPPC is a good drug for control of intestinal nematode parasites.

\section{Aknowledgments}

This work was supported by Korean Research Foundation Grant (KRF-2006-005-J02902).

\section{References}

1. Anderson DL, Roberson EL. Activity of ivermectin against canine intestinal helminths. Am J Vet Res 1982, 43, 1681-1683.

2. Clark JN, Daurio CP, Barth DW, Batty AF. Evaluation of a beef-based chewable formulation of pyrantel pamoate against induced and natural infections of hookworms and ascarids in dogs. Vet Parasitol 1991, 40, 127-133.

3. Clark JN, Daurio CP, Plue RE, Wallace DH, Longhofer SL. Efficacy of ivermectin and pyrantel pamoate combined in a chewable formulation against heartworm, hookworm, and ascarid infections in dogs. Am J Vet Res 1992, 53,517-520.

4. Corwin RM, McCurdy HD, Pratt SE. Effect of febantel against Ancylostoma caninum and Trichuris vulpis infections in dogs. Am J Vet Res 1982, 43, 11001102.

5. Corwin RM, Pratt SE, McCurdy HD. Anthelmintic effect of febantel/praziquantel paste in dogs and cats. Am J Vet Res 1984, 45, 154-155.

6. Dryden MW, Ridley RK. Efficacy of fenbendazole granules and pyrantel pamoate suspension against Toxocara canis in greyhounds housed in contaminated runs. Vet Parasitol 1999, 82, 311-315.

7. Epe C, Pankow WR, Hackbarth H, Schnieder T, Stoye M. A study on the prevention of prenatal and galactogenic Toxocara canis infections in pups by treatment of infected bitches with ivermectin or doramectin. Appl Parasitol 1995, 36, 115-123.

8. Grandemange E, Claerebout E, Genchi C, Franc M. Field evaluation of the efficacy and the safety of a combination of oxantel/pyrantel/praziquantel in the treatment of naturally acquired gastrointestinal nematode and/or cestode infestations in dogs in Europe. Vet Parasitol 2007, 145, 94-99.

9. Greiner EC, Brenner DG, Cox DD, Heaton-Jones DL. Comparison of febantel tablets and Vercom paste against gastrointestinal nematodes of dogs. Vet Parasitol 1992, 41, 151-156.

10. Hopkins TJ. Efficacy of a tablet containing pyrantel embonate, febantel and praziquantel against $\mathrm{T}$ canis in dogs. Vet Rec 1991, 128, 331.

11. Jacobs DE. Control of Toxocara canis in puppies: a comparison of screening techniques and evaluation of a dosing programme. J Vet Pharmacol Ther 1987, 10, 23-29.

12. Klein JB, Bradley RE Sr, Conway DP. Anthelmintic efficacy of pyrantel pamoate against the roundworm, Toxocara canis, and the hookworm, ancylostoma caninum, in dogs. Vet Med Small Anim Clin 1978, 73, 1011-1013.

13. Lloyd S, Gemmell MA. Efficacy of a drug combination of praziquantel, pyrantel embonate, and febantel against helminth infections in dogs. Am J Vet Res 1992, 53, 2272-2273.

14. Mackenstedt U, Schmidt S, Mehlhorn H, Stoye M, Traeder W. Effects of pyrantel pamoate on adult and preadult Toxocara canis worms: an electron microscope and autoradiography study. Parasitol Res 1993, 79, 567578.

15. McTier TL, Siedek EM, Clemence RG, Wren JA, Bowman DD, Hellmann K, Holbert MS, Murphy MG, Young DR, Cruthers LR, Smith DG, Shanks DJ, Rowan TG, Jernigan AD. Efficacy of selamectin against experimentally induced and naturally acquired ascarid (Toxocara canis and Toxascaris leonina) infections in dogs. Vet Parasitol 2000, 91, 333-345.

16. Miró G, Mateo M, Montoya A, Vela E, Calonge R. Survey of intestinal parasites in stray dogs in the Madrid area and comparison of the efficacy of three anthelmintics in naturally infected dogs. Parasitol Res 2007, 100, 317-320.

17. Prelezov PN, Bauer C. Comparative efficacy of flubendazole chewable tablets and a tablet combination of febantel, pyrantel embonate and praziquantel against Trichuris vulpis in experimentally infected dogs. Dtsch Tierarztl Wochenschr 2003, 110, 419-421.

18. Reinemeyer CR, Faulkner CT, Assadi-Rad AM, Burr JH, Patton S. Comparison of the efficacies of three heartworm preventives against experimentally 
The anti-parasitic efficacy of ivermectin and pyrantel pamoate compound against canine Toxocara canis and Trichuris vulpis 295

induced infections with Ancylostoma caninum and Toxocara canis in pups. J Am Vet Med Assoc 1995, 206, 1710-1715.

19. Sharp ML, McCurdy HD. Anthelmintic efficacy of febantel combined with praziquantel in dogs. J Am Vet
Med Assoc 1985, 187, 254-255.

20. Youn HJ, Hong KO, Lee BC and Oh HG. Prevalence of intestinal parasites in dogs and its control in Korea. Korean J Vet Public Health 1995, 19, 257-261. 